\title{
Myocardium area at risk measured with delayed enhancement after scar remodelling compared with T2-weighted cardiac magnetic resonance imaging
}

\author{
Jacob T Lønborg*, Niels Vejlstrup, Anders B Mathiasen, Thomas Engstrøm
}

From 2011 SCMR/Euro CMR Joint Scientific Sessions

Nice, France. 3-6 February 2011

\section{Objective}

We sought to evaluate the accuracy of the endocardial surface area (ESA) method when applied after scar remodelling (three months after initial infarction) using T2-weigthed imaging as reference.

\section{Background}

Cardiac magnetic resonance (CMR) provides an accurate method to determine myocardial infarct size. The myocardium area at risk (AAR) defined, as the part of the myocardium that is endangered during an acute occlusion of a coronary artery, can retrospectively be determined using T2-weigthed CMR imaging or by measuring the ESA of the infarct on delayed enhancement imaging. Previously, the two methods have been compared in the acute phase within one week after the infarction.

\section{Method}

One hundred and sixty-nine patients with ST-elevation myocardial infarction, treated with primary percutaneous coronary intervention, underwent two CMR scans. The first within one week after initial treatment to determine the AAR with T2-weigthed imaging and a second scan three months after initial treatment to measure final infarct size and AAR with the ESA method. The methods were compared using paired $t$-test, correlation coefficient and Bland-Altman analysis.

Rigshospitalet, University Hospital of Copenhagen, Copenhagen, Denmark

\section{Results}

The scans were performed $1.7 \pm 1.2$ days and $89.5 \pm$ 17.3 days after initial treatment, respectively. There was a strong correlation between the two methods $(r=0.86$; $\mathrm{p}<0.001$ ) (Figure 1). The AAR was significantly higher measured with T2-weigthed imaging than with the ESA methods (32.1 $\pm 10.9 \%$ of the left ventricle versus $26.2 \pm$ $10.2 \%$ of the left ventricle; $\mathrm{p}<0.001)$. The mean bias was $5.9 \pm 5.1 \%$ of the left ventricle. The Bland Altman analysis showed that in all patients except four the T2-weighted measurements were higher than the corresponding ESA measurements (Figure 2.). In the four patients with larger AAR with ESA than with T2weigthed imaging the difference ranged $0.1-1.1 \%$ of the left ventricle.

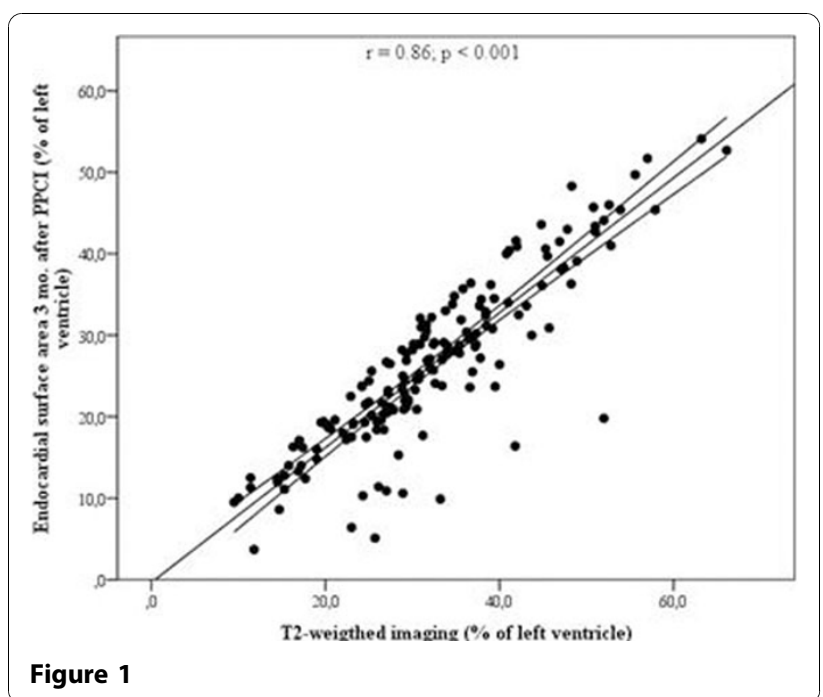

(c) 2011 Lønborg et al; licensee BioMed Central Ltd. This is an open access article distributed under the terms of the Creative Commons :HWed Central Attribution License (http://creativecommons.org/licenses/by/2.0), which permits unrestricted use, distribution, and reproduction in any medium, provided the original work is properly cited. 


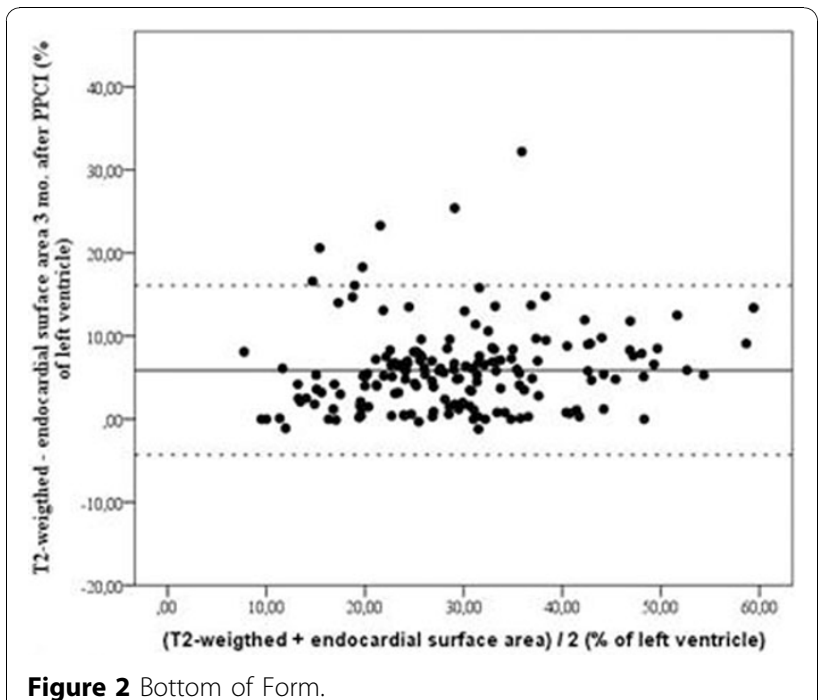

\section{Conclusion}

In the present study, we report a strong correlation between the ESA method performed after scar remodelling and T2-weigthed imaging in the acute phase as regards to measuring the AAR. Therefore, despite an underestimation of the AAR probably due to early intervention, the ESA method performed after scar remodelling is a valid method to determine AAR.

Published: 2 February 2011

doi:10.1186/1532-429X-13-S1-0112

Cite this article as: Lønborg et al:: Myocardium area at risk measured with delayed enhancement after scar remodelling compared with T2weighted cardiac magnetic resonance imaging. Journal of Cardiovascular Magnetic Resonance 2011 13(Suppl 1):0112.
Submit your next manuscript to BioMed Central and take full advantage of:

- Convenient online submission

- Thorough peer review

- No space constraints or color figure charges

- Immediate publication on acceptance

- Inclusion in PubMed, CAS, Scopus and Google Scholar

- Research which is freely available for redistribution

Submit your manuscript at www.biomedcentral.com/submit 